\title{
Roteiros do sertanejo na literatura
}

\author{
Countryman's routes in literature
}

\author{
Raul Azevedo de Andrade Ferreira ${ }^{1}$ \\ Cássia da Silva ${ }^{2}$
}

\begin{abstract}
Resumo: Em um país continental como o Brasil, o território contribui na formação de variadas identidades ligadas aos diferentes espaços que compõem a realidade nacional. A tradição literária, ao conferir tratamento estético a tais formações identitárias, elaboram mitos que estruturam o imaginário social referente à noção de brasilidade. Dentre os mitos assim produzidos, o do sertanejo é central tanto para questão da identidade nacional como para o desenvolvimento da tradição literária. Este trabalho aborda a evolução desse signo a partir da análise de obras características de diferentes momentos do sistema literário brasileiro: Os Sertões, de Euclides da Cunha; Vidas Secas, de Graciliano Ramos; Grande Sertão: Veredas, de Guimarães Rosa; O rio e Morte e Vida Severina, de João Cabral de Melo Neto e Essa Terra, de Antônio Torres. A pesquisa revelou que a representação literária fratura a categoria sertanejo em dois gêneros segundo os diferentes roteiros migratórios que eles realizam: o "sertanejo errante" e o "sertanejo retirante".
\end{abstract}

Palavras-chave: Discurso literário. Identidade nacional. Sertanejo. Os Sertões. Vidas Secas.

\begin{abstract}
In a continental country like Brazil, the territory contributes to the formation of various identities linked to the different spaces that make up the national reality. The literary tradition, by conferring aesthetic treatment to such identity formations, elaborates myths that structure the social imaginary referring to the notion of Brazilianness. Among the myths thus produced, the myth of the sertanejo is central to both the national identity issue and the development of the literary tradition. This work approaches the evolution of this sign from the analysis of characteristic works of different moments of the Brazilian literary system: Os Sertões, by Euclides da Cunha; Vidas Secas, by Graciliano Ramos; Grande Sertão: Veredas, by Guimarães Rosa; O rio and Morte and Vida Severina, by João Cabral de Melo Neto and Essa Terra, by Antônio Torres. The research revealed that the literary representation fractures the sertanejo category in two genera according to the different migratory itineraries that they perform: the errant sertanejo and the sertanejo retirante.

Keywords: Literary discourse. National identity. Sertanejo. Os Sertões. Vidas Secas.
\end{abstract}

\section{Introdução: as identidades territoriais}

No Brasil, a questão da identidade nacional é um tema recorrente, responsável por vários debates que são travados e registrados ao longo de sua história. Sobretudo a partir do fim do pacto colonial, políticos, artistas e intelectuais buscaram, inúmeras vezes, elaborar formulações da brasilidade em suas produções a partir de critérios e valores diversos e relativos às questões políticas, aos interesses de grupos sociais e aos paradigmas dos variados projetos de estado surgidos em diferentes conjunturas (ORTIZ, 2003, p. 8). Quando essas diferentes formulações são analisadas, não se pode deixar de reconhecer certo caráter problemático na suposta unidade da referida etnia nacional, caso optemos pelo termo empregado por Darcy Ribeiro (2015). O problema, que deve ser encarado como uma de nossas principais riquezas, reside nas várias possibilidades de estruturação da brasilidade. Se, como afirma Benedict Anderson (2008, p. 32), uma nacionalidade depende de uma estrutura

\footnotetext{
1 Doutor em Teoria da Literatura (PPGL/UFPE). Professor do curso de Letras da Universidade Regional do Cariri (URCA) Crato, CE, Brasil.. ORCID: https://orcid.org/oooo-0002-6269-8358. E-mail: raul.ferreira@urca.br

2 Aluna do curso de doutorado em Letras da Universidade do Estado do Rio Grande do Norte (UERN), Pau dos Ferros, RN, Brasil. Professora do curso de Letras da Universidade Regional do Cariri (URCA), Crato, CE, Brasil. ORCID: https://orcid.org/oooo-0002-89515849. E-mail: cassia_silv@hotmail.com
} 
simbólica "intrinsecamente limitada", no Brasil tal elemento possui caráter não apenas elástico, como quer o historiador estadunidense, mas também fraturado. As distâncias sociais e econômicas presentes na realidade brasileira produziram antagonismos e contrastes que descambaram em representações da realidade étnica e geográfica de modo a produzir uma fauna de formações identitárias. Assumida a hipótese da unidade do éthos nacional enquanto correta, a imagem da brasilidade é o resultado de um mosaicismo composto por uma variedade de estilhaços.

Darcy Ribeiro (2015, p. 18) indica três forças diversificadoras que devem ser consideradas como fatores dessa pluralidade: a "ecológica", que produz formações culturais a partir das condições ambientais; a "econômica", que opõe gêneros de vida em função das formas de produção; e a "imigração", que introduziu diferentes povos dentro do sincretismo cultural que marca a unidade nacional. Dessa forma, sob a unidade da entidade nacional existe uma série de variantes subculturais que são atravessadas por contradições e antagonismos decorrentes da violência com que se deu o processo de fusão cultural e racial.

Mas apenas quando são simbolizadas por processos discursivos é que tais variantes efetivam as diferentes formações identitárias reunidas sob a rubrica da brasilidade. Os discursos identitários nacionais articulam a diversidade étnica, geográfica e social brasileira nos diferentes projetos políticos, jogos de interesse e concepções de estado nacional. Nesta questão, o discurso literário possui uma função das mais relevantes: elaborar representações estéticas das formações identitárias surgidas nas diferentes conjunturas sociais, históricas e geográficas. Vide, por exemplo, o modo como o índio romântico ofereceu suporte ideológico à monarquia de Dom Pedro II; ou em como a tese da brasilidade mestiça do cientificismo finissecular esteve associada à militância republicana daquele período (ALONSO, 2002, p. 241). Uma das funções sociais da literatura e da arte é conferir uma forma sensível aos sentidos e aos enunciados que circulam no interdiscurso. $\mathrm{O}$ discurso literário é um nó de uma rede de linguagens; é uma elaboração estética de enunciados surgidos em determinadas condições de produção. A brasilidade monárquica é visualizada no índio romântico assim como a brasilidade republicana é representada pelo mito da mulata sensual. Os arquétipos literários, desse modo, cristalizam efeitos de memória que estruturam um imaginário social.

Paradoxalmente, esses efeitos de memória responsáveis pela organização da unidade nacional são produzidos mediante a projeção de valor simbólico justamente sobre os fatores diversificadores da realidade do País, sobre os aspectos naturais e sociais que, desse modo, passam tanto a nos unificar, na medida em que fornecem as peças do mosaico que formam a abstração maior do ser nacional, como a nos diferenciar em uma multiplicidade de subjetividades nacionais. As personagens presentes dentro do sistema literário brasileiro, na medida em que representam as variadas condições raciais, econômicas e ecológicas das localidades brasileiras, bem como dos fluxos migratórios que nelas são desenvolvidos, constroem uma espécie de mitologia do ser nacional: Peri, Rita Baiana, Zeca Tatu, Antônio Conselheiro, Paulo Honório, Gabriela etc., podem ser encarados como representações dos discursos estruturantes das diferentes formações identitárias relativas aos "diversos modos rústicos de ser dos brasileiros” (RIBEIRO, 2015, p. 18), i.e.: os sertanejos, caboclos, crioulos, caipiras, gaúchos etc. O presente trabalho investiga a elaboração de uma dessas formações, o sertanejo, a partir das representações que emergem no discurso literário.

\section{O local do Sertão}

É costume no Brasil, condicionar a realidade humana à realidade geográfica. Sílvio Romero, por exemplo, dividiu a população brasileira em quatro "seções naturais: os habitantes das praias e margens dos grandes rios; os habitantes das matas, os dos sertões, os das cidades" (ROMERO, 1897, p. IV). Ao fazer assim, a extensão do território nacional torna-se fator decisivo para a forma de mosaico da imagem do ser nacional. Na raiz dessa fragmentação, é possível identificar dois cortes simbólicos operados no território nacional pelos discursos es- 
truturantes. Há a divisão política do Brasil em cinco regiões, atualmente esta é a mais imediata e possui suas próprias implicações estéticas, sociais e políticas. Porém, outra divisão, mais antiga e elementar, fundamentada em um corte latitudinal e em outro longitudinal, foi mais relevante para a elaboração do sentido do sertanejo pela literatura.

O "corte latitudinal" opõe o Norte ao Sul do País e elabora duas unidades simbólicas dotadas de aspectos definidos e sempre em tensão na vida nacional: Nordeste e Sudeste. O “corte longitudinal”, por sua vez, opõe o leste ao oeste e produz duas outras localidades: litoral e sertão. Ambos cortes se encontram na raiz dos processos discursivos que fundamentam uma série de textos críticos, políticos e literários que se propõem a realizar uma reflexão sobre o Brasil e uma representação de sua diversidade. Apesar de não se encontrar exatamente na origem da sequência de textos estruturantes do mito do sertanejo, Os Sertões, de Euclides da Cunha, é um "clímax" do sistema cuja descrição é aqui esboçada. É a partir das oposições acima aludidas que Euclides da Cunha desenvolve suas teses. Elas produzem um quadro de representações arquetípicas de subjetividades regionais que o autor dispõe em uma espécie de geometria barroca. O sentido do sertanejo se elucida na medida em que ele é contrastado com os arquétipos relativos a outras regiões do País.

Alinhado ao cientificismo disseminado entre a intelectualidade bacharelesca da época (SCHWARCZ, 1993), Euclides da Cunha apresenta diferentes subjetividades nacionais a partir dos termos oferecidos pelo racialismo determinista-evolucionista. Segundo ele, o meio físico atuaria como um agente diferenciador das raças matrizes da população de maneira a produzir uma variedade de sub-raças mestiças. As várias configurações de clima, relevo e regime de chuvas presentes na natureza brasileira teriam gerado no País aquilo que ele chama de "mestiçagem embaralhada" (CUNHA, 2016, p. 77). É dentro desse quadro que ele retira as oposições que o levarão a uma compreensão do sertão e do sertanejo.

A diferença que ele enxerga entre o Sul e o Norte do País segue esse raciocínio. Enquanto o clima "harmônico" do Sul, que tornaria a região habitável e favorável à agricultura, e que, inclusive, causa a "impressão de um clima europeu” (CUNHA, 2016, p. 87), gerou raças vigorosas, que "melhoram", "evoluem", como o paulista e o gaúcho, antíteses do vaqueiro do Norte (CUNHA, 2016, p. 117), a natureza adversa do Sertão forçaria o homem a uma luta selvagem pela vida (CUNHA, 2016, p. 117). Em tais condições, diametrais às encontradas no Sul, o mestiço torna-se instável, animaliza-se e involui. Forte como um animal que luta pela sobrevivência, mas completamente exausto e incapaz de andar em linha reta, o sertanejo, um "Hércules-Quasímodo" (CUNHA, 2016, p. 115), repete o barroquismo do Sertão, lugar inverso ao locus amoenus do Sul.

Para o autor, as diferenças étnicas e geográficas entre o Norte e o Sul teriam produzido duas realidades sociais e históricas não apenas distintas, mas antagônicas. O Brasil, assim, seria um país que comportaria duas civilizações completamente diferentes:

São duas histórias distintas, em que se averbam movimentos e tensões opostas. Duas sociedades em formação, alheadas por destinos rivais - uma de todo indiferente ao modo de ser da outra, ambas, entretanto, evolvendo sob os influxos de uma administração única. Ao passo que no Sul se debuxavam novas tendências, uma subdivisão maior na atividade, maior vigor no povo mais heterogêneo, mais vivaz, mais prático e aventureiro, um largo movimento progressista em suma - tudo isto contrastava com as agitações, às vezes mais brilhantes mas sempre menos fecundas, do Norte - capitanias esparsas e incoerentes, jungidas à mesma rotina, amorfas $\mathrm{e}$ imóveis, em função estreita dos alvarás da corte remota (CUNHA, 2016, p. 88).

Entre leste e oeste também haveria uma segunda oposição dramática, novamente "causada" pelas condições naturais. Afirma o autor que, a viagem ao ocidente, comece ela de um lugar qualquer da costa, revela um "contraste empolgante" entre uma realidade exuberante e outra pobre, despida das grandes matas: "distantes menos de cinquenta léguas, apre- 
sentam-se regiões de todo opostas, criando opostas condições à vida" (CUNHA, 2016, p. 81). A sociedade sertaneja é apresentada como uma ilha situada em um oceano formado pelo deserto do Sertão. Isolada, ela teria permanecido estagnada, incapaz de evoluir e alheia ao curso da história que se desenvolvia nas demais localidades do País e no restante do mundo, por isso é tida como "velha" e "morta". A guerra de Canudos é entendida como um "refluxo da história" (CUNHA, 2016, p. 191), como o desfecho de um desajuste entre sociedades que se encontram em estágios evolutivos distintos que restara pendente durante séculos. Dramática e irremediavelmente separados, litoral e sertão viveriam cronologias e nacionalidades distintas, colocando em xeque a tese da unidade nacional. No litoral, viver-se-ia de acordo com ideais modernos e civilizados, porém inautênticos, uma vez que teriam sido tomados de empréstimo de outras nações. Afastado da realidade sertaneja, o Brasil litorâneo aparece como um país apartado de si mesmo:

Vivendo quatrocentos anos no litoral vastíssimo, em que pelejam reflexos da vida civilizada, tivemos de improviso, com herança inesperada, a República. Ascendemos, de chofre, arrebatados na caudal dos ideais modernos, deixando na penumbra secular em que jazem, no âmago do país, um terço de nossa gente. Iludidos por uma civilização de empréstimo; respingando, em faina cega de copistas, tudo o que de melhor existe nos códigos de outras nações, tornamos, revolucionariamente, fugindo ao transigir mais ligeiro com as exigências da nossa própria nacionalidade, mais fundo o contraste entre o nosso modo de viver e o daqueles rudes patrícios mais estrangeiros nesta terra do que os imigrantes da Europa. Porque não no-los separa um mar, separam-no-los três séculos... (CUNHA, 2016, p. 191).
Entre os mestiços do litoral e os do sertão, Euclides da Cunha também enxerga antagonismos semelhantes aos postulados entre os arquétipos elaborados a partir da oposição Norte vs. Sul. O mestiço sertanejo seria um tipo etnológico cujo processo evolutivo encontrar-se-ia concluído, ao passo que o mestiço do litoral ainda seria um tipo em formação. O fim do processo evolutivo dos mestiços sertanejos teria sido possibilitado pelo isolamento do homem no interior da "terra ignota". Insulada em um local cujo acesso apresentaria "obstáculos mais sérios que a rota agitada dos mares e das montanhas" (CUNHA, 2016, p. 81), a população sertaneja teria se reproduzido livre da influência de agentes externos. Essa seria a principal diferença entre eles e os "mestiços neurastênicos do litoral" (CUNHA, 2016, p. 115), cujo atraso mental se daria em função de uma "mestiçagem perturbada" (CUNHA, 2016, p. 107) pela presença de imigrantes vindos de outros países.

Na geometria barroca de Euclides da Cunha, a imagem do sertão e de seus habitantes é desenhada dentro de uma "triangulação simbólica"4 do território nacional. Nesse triângulo, cada cateto dispõe as diferentes realidades geográficas em antagonismos extremos. Assim, o "Norte" passa a ser o oposto negativo do "Sul", tal como o "sertão" aparece como o oposto negativo do "litoral". Surgido no século XVI como referência às terras de dentro do continente, em oposição às terras de fora, do litoral (TELES, 2009, p. 77), o sertão agora passa a ser localizado mais ao noroeste do País e torna-se um signo dotado de uma série de implicações sociais e econômicas. No triângulo formado pelos vértices produzidos pelos cortes latitudinal e longitudinal, o sertão é situado onde os dois polos negativos se recobrem, i.e.: nos pontos valorados negativamente pelo discurso vocalizado pelo autor. O sertão, assim, torna-se antônimo tanto

\footnotetext{
3 Cumpre considerar que o evolucionismo social considerava a mestiçagem como algo negativo para a composição da população, pois seria a causa para a degeneração mental dos indivíduos: "a mistura de raças mui diversas é, na maioria dos casos, prejudicial. Ante as conclusões do evolucionismo, ainda quando reaja sobre o produto o influxo de uma raça superior, despontam vivíssimos estigmas da inferior. A mestiçagem extremada é um retrocesso" (CUNHA, 2016, p. 110).

4 A imagem do Brasil como um triângulo já aparecera no Compêndio de história da literatura brasileira, de Sílvio Romero e João Ribeiro (2001, p. 26): "O Brasil é um possante triângulo, cuja porção central, a antiga ilha, o planalto, está hoje, como dissemos, cercada por quatro grandes depressões [...]”.
} 
do litoral como do Sudeste. A partir de então, a natureza da região consolida-se no imaginário político e social como agente agressor da sociedade, causa da fome e da pobreza, efeito de sentido que naturaliza as desigualdades produzidas pela forma como as relações sociais lá se dão (CASTRO, 2001). O sentido do sertanejo é gerado dentro deste triângulo: ele é "instável” e "animalizado" enquanto os arquétipos sulistas apresentam-se como "harmônicos" e "humanizados"; raça "definida" e "íntegra" ao passo que o litorâneo é caracterizado como "perturbado" e "incompleto".

Apesar das categorias negativas que emprega e do racismo do esquema de seu pensamento, Euclides da Cunha enxerga no sertão e no sertanejo o local e o arquétipo mais autênticos da nacionalidade. Apesar de desconectá-lo do restante do país e de percebê-lo como anacrônico e estagnado, o isolamento produzido pelo sertão teria permitido que a sua população permanecesse ao largo dos fluxos migratórios que teriam "agravado" a condição mestiça do povo brasileiro e perturbado a sua condição nacional. Diante disso, Euclides da Cunha afirma que "aquela rude sociedade, incompreendida e olvidada, era o cerne vigoroso da nossa nacionalidade" (CUNHA, 2016, p. 103). Esse valor nacional que o sertão e o sertanejo então adquirem confere importância aos signos que, desse modo, constituem topoi consolidados no sistema literário brasileiro.

Surgido nos anos finais do século XIX, o tópos sertanejo acaba por transcender as implicações políticas conjunturais e a linguagem cientificista de suas condições de produção originais. Ao longo do século $\mathrm{XX}$, ele adquire novas linguagens e as suas representações são desdobradas de modo a cobrir toda a complexidade da questão que o assunto procura remeter, o que faz com que ele se torne uma temática central para a formulação de um éthos nacional. Pensar e representar a realidade sertaneja torna-se pensar e representar os diferentes "brasis" e os seus problemas históricos, sobretudo o abismo social que permanece em nossa sociedade como uma ferida que resiste à cicatrização.

\section{A ilha e a errância}

A análise das representações do sertanejo pela literatura suscitam que também se considere os deslocamentos realizados no interior ou a partir do sertão. Deve-se, portanto, relacionar o tópos sertanejo ao tópos migrante. Esta imposição é colocada na medida em que a literatura representa uma população subalternizada, pois, como lembra Armando Gnisci (2003, p. 1), "os dominados tendem sempre mais a mover-se, a deslocar-se". Euclides da Cunha (2016, p. 136) alinha-se a esse entendimento quando se refere ao sertanejo como um "nômade ou mal fixo à terra”. A partir de seus roteiros, o signo "sertanejo" fragmenta-se em dois outros: o "errante", atribuído àquele que se desloca no interior do sertão sem conseguir ultrapassar seus limites, e o "retirante", termo aqui empregado para caracterizar quem se desloca do sertão para um dos outros polos opostos, i.e.: o sertanejo que migra para o litoral e o que migra para o Sudeste.

No drama do "errante", o sertão aparece como um espaço "insulado". Dentro dele, anda-se por suas veredas em círculos e delas nunca se sai. Aqui, movimento e deslocamento não se confundem, pois as caminhadas que não cruzam as fronteiras do sertão-ilha não proporcionam uma transformação efetiva da condição social, econômica e existencial do sertanejo. Os movimentos da errância, portanto, mascaram certa imobilidade. Apenas quando termina na conquista do sedentarismo é que se tem o deslocamento efetivo. Mas a seca e as violências sociais empurram o sertanejo em uma interminável perambulação sem destino. Uma errância que o faz incapaz de ir a um local diverso do já conhecido e onde ele encontra-se constantemente ameaçado pela fome e pela morte. A vida sedentária aparece apenas quando projetada em um outro mundo, sempre sonhado e visto como muito distante, um mundo estrangeiro, externo ao sertão-ilha.

O Antônio Conselheiro de Euclides da Cunha é o primeiro esboço do sertanejo errante. Natural de Quixeramobim, teve uma vida pacata e estável até sofrer uma metamorfose psicológica provocada pelo 
adultério de sua esposa. É esse o momento em que ele se transforma no sertanejo errante. O sertão recluso e distante abre-lhe a possibilidade de uma morte $\mathrm{e}$ de um renascimento simbólicos que o convertem no "anacoreta sombrio" de "cabelos crescidos até os ombros, barba inculta e longa, face escaveirada" (CUNHA, 2016 p. 155). Ele, então, abandona hábitos sedentários e gasta anos peregrinando pelas cidades da região realizando suas pregações e arrastando uma multidão de seguidores:

[...] em toda esta área não há, talvez, uma cidade ou povoado onde não tenha aparecido. Alagoinhas, Inhambupe, Bom Conselho, Jeremoabo, Cumbe, Mocambo, Maçacará, Pombal, Monte Santo, Tucano e outros, viram-no chegar, acompanhado da farândola de fiéis" (CUNHA, 2016, p. 160).

Quando perseguido pelo Governo, o Conselheiro refugia-se na reclusão oferecida pelos sertões, pois os praças não se aventurariam em suas brenhas. No "sertão-ilha" não se entra como não se sai. E assim ele decide vagar sem destino certo dentro dos limites da "terra ignota", e "os crentes acompanharam-no. Não inquiriam para onde seguiam. "Atravessaram serranias íngremes, tabuleiros estéreis e chapadas rasas, longos dias, vagarosamente, na marcha cadenciada pelo toar das ladainhas e pelo passo tardo do profeta..." (CUNHA, 2016, p. 171).

É possível considerar Riobaldo, de Grande Sertão: Veredas, uma formulação singular do sertanejo errante, pois nesse caso a atividade ideadora não se dirige apenas à fantasiação do outro mundo, ela assume um caráter especulativo que propicia uma forma de transcendência. As suas ambulações permitem-lhe iniciar um processo humanizador de seu espírito. Riobaldo, na verdade, como seu próprio nome indica, deve ser considerado uma síntese da tese que é o "errante" e de sua "antítese", o retirante. De alguma forma, ele retira-se sem sair do sertão. Por uma questão de economia de espaço, por ora essa questão será deixada de lado, mas ainda assim será anotado aqui uma indicação rápida do arquétipo do sertanejo aprisionado nas fronteiras de sua localidade. Trata-se do episódio no qual o protagonista encontra um grupo estranho de sertanejos entocados no "fundo do sertão" (ROSA, 2006, p. 390) e que impedem a passagem pela vereda que corta suas terras. São os catrumanos - regionalismo mineiro para caipira, matuto - que habitam "por esses lugares, que o nome não se soubesse”, "sertão churro" (ROSA, 2006, p. 381). São pessoas de feições estranhas, por demais diversas dos jagunços companheiros do narrador. De índole perversa e portadores de armas de outras idades, a sua condição primitiva é indicada pela precária espiritualidade e uma maior proximidade com a condição animal: "vinham tapados de Deus, assim nos ocos. Nem não saíam dos solapos, segundo refleti, dando cria feito bichos, em socavas" (ROSA, 2006, p. 384).

Considerando que Riobaldo também é um sertanejo, é possível entender o sertão de Guimarães Rosa como uma região estruturada em camadas, como uma cebola. Assumindo esse princípio, as errâncias transcendentalizantes do narrador ocorreriam nas periferias, pois em seu íntimo profundo o sertão assume a forma de ilha. Lá, o homem para no tempo, perde-se em uma dimensão própria e animaliza-se: "que acontecia era de serem só esses homens reperdidos sem salvação naquele recanto lontão de mundo, groteiros dum sertão, os catrumanos daquelas brenhas" (ROSA, 2006, p. 384).

Se em Os Sertões temos o arquétipo do "errante" somente esboçado, e em Grande Sertão: Veredas apenas indicado, em Vidas Secas, de Graciliano Ramos, encontramos o tópos acabado. Construído sobre a errância de Fabiano e de sua família na busca por melhores condições de existência, esse é o texto que mais se aproveita das categorias de "sertão-ilha" e de sertanejo "errante". O início e o fim da narrativa indicam que, na sina perambulatória da família, não há perspectivas de mudança da condição de errante. O sertão jamais é atravessado, as andanças são realizadas a contragosto, são forçadas, o desejo íntimo, metaforizado pela cama sonhada por Sinhá Vitória, é o do enraizamento; mas forças naturais, sociais e econômicas constantemente empurram os sertanejos em sucessivos ciclos migratórios que jamais se resol- 
vem, pois o movimento nunca os levam a lugar algum, já que é destituído de sentido: "o vaqueiro precisava chegar, não sabia onde” (RAMOS, 2005, p. 10).

Os lugares que Fabiano encontra no fim de cada ciclo de caminhadas nunca são pontos de chegada, são sempre novos pontos de partida: casas desertas, fazendas mortas, locais já abandonados por outras famílias. É para se suspeitar que todos no sertão estão circulando à procura de um pouso inexistente. Duas são as ordens de "forças empuxantes". A primeira delas é formada pela natureza agressiva, aqui traduzida pelas representações da seca, da fome e da morte. Estes são agentes intrincados e sequenciais de uma mesma realidade adversa. A seca provoca a fome e essa, a morte, constantemente lembrada pelos voos dos urubus, companheiros infatigáveis do caminho. Durante os seus curtos períodos de parada, o errante permanece em estado de constante vigília, tentando antecipar o momento exato de levantar mais uma vez o seu acampamento e iniciar mais uma tentativa de imigrar do sertão

A narrativa de Graciliano Ramos confere forma e aparência a um discurso sobre a seca que parte das elites econômicas, convence a sociedade e naturaliza graves problemas sociais. Apesar disso, Graciliano transforma esse discurso na medida em que a sua narrativa passa a representar questões sociais relativas ao drama do sertanejo. Esse é o principal ponto de inflexão que diferencia o seu livro do de Euclides da Cunha. No determinismo d'Os Sertões, tem-se apenas a terra agressora e o homem vitimado. A guerra então aparece como o influxo de uma natureza em erupção. Em Vidas Secas, além das forças naturais, fatores socioeconômicos também atuam no empurrão, também eles impedem o enraizamento.

Os fatores sociais e econômicos aparecem quando a "pobreza" e a "subalternidade" do sertanejo são representadas. Esses dois fatores constituem a segunda força "empuxante" que obriga a família à errância. Vidas Secas coloca em questão a distribuição injusta do direito à terra. Animada por ter encontrado uma fazenda improdutiva e abandonada, a família cria esperanças de fixar-se em um local, de enfiar-se na terra como tatu, de prender-se a ela como um mandacaru, mas logo em seguida eles reparam no estrato social em se encontram e percebem seu engano: se a terra não é possuída, a família não pode fixar-se nela. Como permanecer em um local onde eles não podem ser recebidos senão como hóspedes?: "Entristeceu. Considerar-se plantado em terra alheia! Engano. A sina dele era correr mundo, andar para cima e para baixo, à toa, como judeu errante. Um vagabundo empurrado pela seca. Achava-se ali de passagem, era hóspede" (RAMOS, 2005, p. 19).

As relações sociais que o sertanejo é forçado a ter são marcadas pela violência estratificada. De cima, todas as forças agridem o indivíduo. O governo na figura do soldado amarelo e do coletor de impostos; as elites econômicas na figura do patrão. Todos, autoritariamente, roubam e violentam Fabiano e sua família. O soldado pelo jogo de cartas; o governo pela taxação da carne de porco; o patrão pelas contas de seu trabalho. Os episódios recorrentes de agressão à sua condição humana levam o sertanejo à submissão resignada. Fora da família, o sertanejo é destituído de toda espécie de poder, dentro dela, os pais redirecionam o autoritarismo agressivo aos filhos, que são conduzidos por eles através da violência física e moral. Os ciclos das errâncias são também uma repetição interminável de experiências animalizantes:

E, pensando bem, ele não era um homem: era apenas um cabra ocupado em guardar coisas dos outros. Vermelho, queimado, tinha os olhos azuis, a barba e os cabelos ruivos; mas como vivia em terra alheia, cuidava de animais alheios, descobria-se, encolhia-se na presença dos brancos e julgava-se cabra (RAMOS, 2005, p. 18).

A condição animal é uma consequência direta dessa errância estática. Parado, Fabiano e sua família animalizam-se. Quem consegue a travessia torna-se um "homem humano". Quem resta preso no sertão-ilha embrutece, o que de alguma forma acaba sendo proveitoso na lida pela sobrevivência: "Isto para ele era motivo de satisfação. Sim senhor, um bicho, capaz de vencer dificuldades" (RAMOS, 2005, p. 19). Para o sertanejo oprimido, a única possi- 
bilidade de recuperar a humanidade é a superação da subalternidade, feito que Fabiano por um momento espera atingir entrando no cangaço e executando violências ainda mais extremas, como o assassinato do soldado amarelo. Mas logo essa saída é descartada e a superação passa a ser indicada pelas projeções realizadas por Sinhá Vitória.

Fabiano e Sinhá Vitória formam um par antitético que divide o núcleo da família entre a atividade prática e a atividade ideadora. Essa dicotomia pode ser observada a partir dos destinos que os pais apontam aos filhos. Fabiano e Sinhá Vitória são vetores de possibilidades diversas direcionadas aos dois meninos. Homem prático, pragmático, Fabiano ensina a animalidade que conferirá a resiliência necessária à sobrevivência no sertão. Ao menino mais novo, a quem é mais ligado, ele aponta para a repetição de seu destino: ser vaqueiro como ele. O menino mais velho, por sua vez, liga-se à Sinhá Vitória e com ela aprende o domínio simbólico inerente à linguagem.

Essa dicotomia revela-se também no contraste oferecido pelo pessimismo de Fabiano, que não acredita na possibilidade de que as suas errâncias algum dia irão levá-lo a uma realidade diversa da realidade a que estão amarrados, e o otimismo de Sinhá Vitória, que acredita que os seus filhos poderão ter uma vida diferente em um outro lugar. A desesperança de Fabiano deriva de sua limitada capacidade de abstrair. Como um bicho, vê apenas o mundo pequeno que se encontra à sua frente, de modo que para ele não há outra possibilidade senão a repetição da mesma vida. Sinhá Vitória, por sua vez, é capaz de idear o mundo grande situado além dos limites do Sertão e, por isso, procura mentalmente novas possibilidades. O desfecho da narrativa é consagrado ao embate entre esses dois modos existenciais antagônicos. Quando pergunta ao marido o que fariam os dois filhos depois de crescidos, Sinhá Vitória contra-argumenta Fabiano:

- Vaquejar, opinou Fabiano. Sinhá Vitória, com uma careta enjoada, balançou a cabeça negativamente, arriscando-se a derrubar o baú de folha. Nossa Senhora os livrasse de semelhante desgraça. Vaquejar, que ideia! Chegariam a uma terra distante, esqueceriam a caatinga onde havia montes baixos, cascalhos, rios secos, espinho, urubus, bichos morrendo, gente morrendo. Não voltariam nunca mais, resistiriam à saudade que ataca os sertanejos na mata. Então eles eram bois para morrer tristes por falta de espinhos? Fixar-se-iam muito longe, adotariam costumes diferentes (RAMOS, 2005, p. 123).

O que Sinhá Vitória indica é a travessia do Sertão. Por ela, uma outra vida seria alcançada, uma vida onde a condição animal seria superada e os dois ideais buscados pelos sertanejos - o sedentarismo e a humanidade - seriam finalmente realizados. O meio encontrado para isso é a realização de um deslocamento que os permita atingir um ponto de chegada. Sinhá Vitória indica a outra metade que se junta ao errante e completa o signo sertanejo, a antítese do errante: o "retirante".

\section{$3 \mathrm{O}$ rio e a retirada}

A questão migratória também fundamenta o segundo gênero que complementa a categoria sertanejo. Desta vez, esse surge como aquele que consegue sair do sertão e atinge o outro mundo que aparece nas fantasias de Sinhá Vitória. Nesse caso, a imagem da ilha é substituída por outra dotada de um poderoso valor simbólico: o rio. O retirante não está aprisionado, ele é aquele que busca realizar a travessia partindo do sertão e terminando no litoral. O rio conecta o sertão às outras localidades do País e possibilita o escape, o deslocamento que levará aos demais vértices do triângulo nacional. Irrigado, o sertão torna-se um local de passagem; um nó de partida de uma rede migratória, de movimentos sucessivos de migrações e remigrações. O rio transforma todos os locais em pontos de passagem. Em Vidas Secas, os rios estavam secos e a única possibilidade que restava era circular pelo Sertão. O errante é o sertanejo das vazantes; o retirante, por sua vez, é o sertanejo que acompanha o fluxo do rio.

Os rios desinsulam o deserto e complicam as identidades geográficas brasileiras, agora devidas 
não apenas à variedade de localidades apresentadas pelo território, mas também às possibilidades de trânsito dentro dessa variedade. Importantes fatores de integração nacional, os rios compensam os antagonismos das localidades estabelecidas pelos recortes traçados por Euclides da Cunha. Para Sílvio Romero (2002), a rede fluvial é o que garante unidade política e social à heterogênea realidade brasileira. Euclides da Cunha, por sua vez, comenta a importância do Rio São Francisco para a composição da nacionalidade quando ele leva os homens do Sul ao Norte. Para ele, o Velho Chico "erigia-se desde o princípio com a feição de um unificador étnico, longo traço de união entre as duas sociedades que não se conheciam" (CUNHA, 2016, p. 100). O rio transforma o sertanejo no retirante: aquele que, seguindo para o litoral ou para o Sul, almeja o sedentarismo que o permita reconhecer-se como "homem humano".

Em Morte e Vida Severina, de João Cabral de Melo Neto (2006), encontramos um exemplo de retirante longitudinal na narrativa de Severino. Em busca de uma ocupação, de alguma forma de subsistência, o retirante decide seguir o rio Capibaribe, que é como seu guia pela estrada que parte do Sertão e segue até o litoral, no Recife. Determinado por seu roteiro, o sertanejo confunde o seu destino com o do rio, depende dele para seguir viagem. Ele seco, implica a interrupção da retirada:

Pensei que seguindo o rio
eu jamais me perderia:
ele é o caminho mais certo,
de todos o melhor guia.
Mas como segui-lo agora
que interrompeu a descida?
Vejo que o Capibaribe,
como os rios lá de cima,
é tão pobre que nem sempre
pode cumprir sua sina
e no verão também corta,
com pernas que não caminham (MELO NETO,
2006, p. 176).

Unidos em um mesmo destinamento, rio e sertanejo emprestam seus traços um ao outro. O rio assume os traços humanos assim como o homem assume os traços fluviais. Em um poema escrito dois anos antes, em 1953, intitulado "O rio ou relação da viagem que faz o Capibaribe de sua nascente à cidade do Recife", temos o mesmo drama da retirada, mas o protagonista-narrador é o próprio rio Capibaribe, que desce do alto sertão, na lagoa da Estaca, para desaguar no Recife. Rio e retirante são dois heróis permutáveis, os dois poemas desenvolvem a mesma história: a retirada para o litoral.

O rio antropomorfiza-se, deixa a condição de navegado e assume a de navegante. Um exemplo é o momento em que é descrita a sua passagem pelo mar de canaviais atravessados durante a passagem pela zona da mata: "através deste mar,/ como um barco na corrente,/ mesmo sendo eu o rio,/ que vou navegando parece" (MELO NETO, 2006, p. 134). Os homens também aparecem como rios, como quando é narrada a leva de trabalhadores que engrossa a procissão dos retirantes: "A gente das usinas/ foi mais um afluente a engrossar/ aquele rio de gente/ que vem além do Jacarará" (MELO NETO, 2006, p. 135). Considerando o desenvolvimento do tópos aqui abordado, o que se tem é a substituição da metáfora do "homem-animal" pela do "homem-rio": homem e rio identificam-se quando ambos atendem ao chamado do mar: "Sempre pensara em ir/ caminho do mar./ Para os bichos e rios/ nascer é já caminhar./ Eu não sei o que os rios/ têm de homem do mar; sei que se sente o mesmo/ e exigente chamar" (MELO NETO 2006, p. 119).

Como já foi aqui anotado antes, a questão da retirada é inicialmente colocada pela ideação do sertanejo errante. Quando esse transforma-se no retirante, as projeções são confrontadas pela realidade concreta. Esse é o drama constituinte de seu enredo: a realidade que contradiz a expectativa. $\mathrm{O}$ errante quer fugir do sertão para escapar da seca, da fome, da morte, da desigualdade, das injustiças: males naturais e sociais que assolam a realidade sertaneja. O sertanejo, então, assume o modo retirante na esperança de encontrar o El Dorado onde tais males encontrar-se-iam superados, mas a travessia revela que os mesmos problemas estão distribuídos ao longo do caminho bem como no ponto de chegada. 
Em seu roteiro, o rio Capibaribe trava contato com a "Usina", símbolo das grandes propriedades rurais que tolhem os pequenos agricultores. Severino, por sua vez, segue sempre acompanhado daquela de quem fugia: a morte. Todos os encontros travados ao longo do caminho e já no Recife são marcados por episódios fúnebres. A chegada no litoral é igualmente frustrante para o Capibaribe. Antes de descer ao mar, ele lamenta o destino dos retirantes empurrados pela seca e vomitados pela "Usina". Com empatia, enxerga eles construírem suas palafitas na lama dos manguezais. Apesar de se encontrarem na cidade "oficial", os retirantes não conseguem efetivamente estar nela. A cidade é interditada aos sertanejos emigrados, que então fundam uma cidade paralela onde lhes seja permitido alguma espécie de vida. Nessa cidade de lama a humanidade buscada não é encontrada; ela é bem diferente da idealizada por Sinhá Vitória. O rio enxerga a frustração dos retirantes que, no fim da viagem, encontraram um outro deserto, diferente do já conhecido apenas em seu nível de umidade: "A um rio sempre espera/ um mais vasto e ancho mar./ Para a gente que desce/ é que nem sempre existe esse mar,/ pois eles não encontram/ na cidade que imaginavam mar/ senão outro deserto/ de pântanos perto do mar." (MELO NETO, 2006, p. 142). Através de Severino, percebemos a mesma frustração. Fugindo da morte, ele descobre no fim da jornada que seguia justamente em direção a ela:

\footnotetext{
Nunca esperei muita coisa,

é preciso que eu repita.

Sabia que no rosário das cidades e das vilas, e mesmo aqui no Recife ao acabar minha descida, não seria diferente a vida de cada dia: que sempre pás e enxadas foices de corte e de capina, ferros de cova, estrovengas o meu braço esperariam. Mas se este não mudasse seu uso de toda vida,
}

\author{
esperei, devo dizer, \\ que ao menos aumentaria \\ na quartinha, a água pouca, \\ dentro da cuia, a farinha, \\ o algodãozinho da camisa, \\ ou meu aluguel com a vida. \\ E chegando aprendo que, \\ nessa viagem que eu fazia, \\ sem saber desde o Sertão, \\ meu próprio enterro eu seguia. \\ Só que devo ter chegado \\ adiantado de uns dias; \\ o enterro espera na porta: \\ o morto ainda está com vida \\ (MELO NETO, 2006, p. 192).
}

Buscando a vida, Severino encontrou apenas a morte; procurando condições para viver de forma digna, descobre apenas mais miséria. Ele então se questiona se não seria melhor jogar-se no rio que acompanhou a sua caminhada e a sua esperança. Porém, sendo um auto de natal, o poema não poderia terminar em morte. O nascimento do filho do carpina, se não responde definitivamente à pergunta que Severino se coloca, ao menos lhe diz que a vida, ainda que severina como a dos sertanejos, onde quer que eles estejam, é tão inevitável como a morte.

Desfecho distinto ocorre em Essa Terra, romance de Antônio Torres (2014) publicado em 1976. Nele, há a narrativa de Totonhim sobre o destino de sua família, especialmente sobre o de seu irmão mais velho, Nelo, que migra para São Paulo, mas depois retorna para a sua terra natal, o povoado de Junco, no interior da Bahia, onde comete suicídio.

Para o retirante que segue pelo cateto longitudinal, São Paulo aparece como o local da prosperidade econômica; é a cidade do sucesso e da riqueza. Tem-se até a impressão que o sertanejo nem busca a cidade, ela parece magnetiza-lo com as miragens de um oásis ilusório: "Nelo descobriu que queria ir embora no dia em que viu os homens do jipe [...] sonhando todas as noites com a fala e as roupas daqueles bancários - a fala e a roupa de quem, com certeza, dava muita sorte com as mulheres" (TORRES, 2014, p. 63). 
Na rota para o sul, o rio é substituído pelas estradas e seus caminhões, que agora cumprem a função de manter a nação integrada. Outra alteração no tópos é a entrada da questão do consumismo: se antes a retirada aparecia como algo vital, provocada pela necessidade de se escapar à morte, agora ela deixa de ser uma questão de sobrevivência e liga-se ao modus vivendi capitalista. A confusão entre consumo e felicidade encontra-se na raiz da idealização do Sul: "Dinheiro. Dinheiro. Dinheiro. Cresce logo menino pra você ir para São Paulo" (TORRES, 2014, p. 63).

Uma terceira modificação digna de nota reside no fato de se ter a representação completa da rede na qual todo e qualquer processo migratório se desenvolve. A migração é um fenômeno social complexo que acontece dentro de um circuito onde os migrantes migram e remigram. Até então, tinha-se apenas o retirante em seu movimento de ida; agora, tão importante quanto a retirada é o retorno; tão importante quanto aquele que foi são aqueles que ficaram: a família que permanece no sertão e segue alimentando as ilusões enquanto depende economicamente do filho que partiu. Quando se considera a rede migratória em sua totalidade, a condição de migrante implica diretamente a condição de "retornado": "o retorno desempenha, de fato, um papel estrutural elementar na organização e na evolução dos fluxos migratórios" (FAZITO, 2010, p. 90). O drama do retornado não é mais a decepção com a cidade que lhe é interditada, mas enfrentar aquilo que ele julga ser o seu fracasso: ter que voltar.

O retorno de Nelo pode ser entendido como um atropelo da realidade sobre os sonhos de toda a família. Diferentemente de Severino, Nelo opta pelo suicídio, o que parece indicar que o retorno efetivo não é uma possibilidade concreta, apesar de exercer "uma força motriz capaz de se materializar em normas, valores e comportamentos de indivíduos e grupos" (FAZITO, 2010, p. 92). Mesmo sem sucesso, a migração de Nelo continua alimentando as estruturas simbólicas que colocam o Sul como o local da salvação para o sertanejo. O seu suicídio não é capaz de fraturar a idealização realizada pela família. Mesmo morto, Nelo ainda é um agente mediador da rede migratória Norte-Sul. É durante o enterro do irmão que Totonhin, o narrador, resolve ir para São Paulo:

O enterro foi pago com dinheiro emprestado a juros [...] Teu pai não sabe se vai ter dinheiro para comer, daqui pra frente, quanto mais para pagar os juros do enterro de um filho [...] Nelo, querido, [...] é bem capaz que eu esteja começando a te compreender.

- Saiba de uma coisa, papai. Eu vou embora. [..]

- Mas para onde você vai?

- Para São Paulo (TORRES, 2014, p. 168).

Mais uma vez, o Sudeste aparece como o espaço de salvação para o sertanejo que procura fugir da miséria, das dívidas e do "atraso" socioeconômico. Apesar da morte do irmão, a família continua a ideação pela qual o sertanejo converte-se em um migrante; ele permanece desejando a vida na cidade e, a acreditar que apenas ela permitirá a superação das dificuldades. Assim, a necessidade da retirada cristaliza-se no sentido que a literatura conferiu ao signo "sertanejo".

\section{Considerações finais}

Quando se considera a questão da identidade nacional, não se pode perder de vista o funcionamento das discursividades presentes no sistema literário brasileiro. A literatura, segundo os procedimentos linguísticos que lhe são próprios, sistematiza e confere forma sensível aos discursos que pretendem dar conta do éthos nacional. Apesar de encontrarem-se vinculados a projetos de estado nacional e a posicionamentos ideológicos específicos surgidos em diferentes conjunturas, tais discursos, ao adquirirem a condição de literários, passam a funcionar segundo uma lógica própria relativa ao funcionamento da série literária a que pertencem. A instituição literária, portanto, possui um funcionamento híbrido, pois ao mesmo tempo em que é porosa às discursividades de outras naturezas, é dotada também de uma dinâmica relativamente autônoma onde os temas e as suas formas evoluem a partir do estado prévio de seus topoi. 
No que diz respeito à questão da identidade brasileira, as diferentes estetizações das formas de subjetividade que compõem o ser nacional possuem suas séries literárias específicas. A partir de alguns textos literários representativos, neste trabalho foi analisada a série referente a uma dessas formas de subjetividade: o sertanejo. Esse signo recebeu diferentes formulações literárias ao longo da história, sendo o Os Sertões um momento dos mais importantes para o desenvolvimento do mito do sertão e do sertanejo. Depois do livro de Euclides da Cunha, a categoria "sertanejo" fragmenta-se em dois gêneros: o "errante" e o "retirante". As duas definições dependem diretamente de fluxos migratórios específicos: um que se restringe à perambulação realizada dentro das fronteiras do sertão e outro que pode se desenvolver em um sentido latitudinal ou longitudinal. Elas também se encontram condicionadas por meio dos entendimentos que são construídos sobre o espaço geográfico característico do sertanejo. Para o "errante", o sertão aparece na forma de um espaço insulado, uma prisão que isolaria o indivíduo em uma realidade agressiva, mas que também o preservaria de contaminações que descaracterizariam a sua "integridade" cultural. Para o "retirante", o sertão assume a forma de um local de passagem; é um espaço de onde se sai, mas é também um espaço para onde se volta. Representados pela literatura, tais deslocamentos problematizam as estruturas simbólicas que informam os sentidos das diversas territorialidades brasileiras e relativizam as dicotomias que foram empregadas na elaboração dos entendimentos sobre a realidade nacional.

\section{Referências}

ALONSO, Angela. Idéias em movimento: a geração de 1870 na crise do Brasil-Império. São Paulo: Paz e Terra, 2002. https:// doi.org/10.11606/issn.1808-8139.voi2p123-127

ANDERSON, Benedict. Comunidades imaginadas: reflexões sobre a origem e a difusão do nacionalismo. São Paulo: Companhia das Letras, 2008.

CANDIDO, Antonio. Formação da literatura brasileira: momentos decisivos. Belo Horizonte: Itatiaia, 1981.

CAMPOS, Luciene Lemos de; RODRIGUES, Luciano. Migrantes e migrações: entre a história e a literatura.
Albuquerque: revista de História, Campo Grande, v. 3 n. 5 p. 33-49, jan./jun. 2011.

CASTRO, Iná Elias de. Natureza, imaginário e a reinvenção do Nordeste. In: ROZENDAHL, Z.; CORRÊA, R. L. (org.) Paisagem, imaginário e espaço. Rio de Janeiro: EDUERJ, 2001. p. 103-133.

CUNHA, Euclides da. Os sertões. São Paulo: Ubu editora/ Edições Sesc São Paulo, 2016.

FAZITO, Dimitri. Análise de Redes Sociais e Migração: dois aspectos fundamentais do "retor-no". Revista Brasileira de Ciências Sociais, São Paulo, v. 25, n. 72, fev., 2010. https://doi. org/10.1590/s0102-69092010000100007

GNISCI, Armando. Migração e literatura. Revista Eletrônica do Instituto de Humanidades, Duque de Caxias, v. II, n. VII, p. 1-8, out./dez., 2003.

HOLANDA, Sérgio Buarque de. Visão do paraíso. São Paulo, Brasiliense, 1992.

MELO NETO, João Cabral de. O rio. In: MELO NETO, João Cabral de. Obra completa. Rio de Janeiro: Nova Aguilar, 2006. https://doi.org/10.11606/t.8.2017.tde-02062017-101821

MELO NETO, João Cabral de. Morte e Vida Severina. In: MELO NETO, João Cabral de. Obra completa. Rio de Janeiro: Nova Aguilar, 2006. https://doi.org/10.5216/lep.v13i1.11920

ORTIZ, Renato. Cultura brasileira e identidade nacional. São Paulo: Brasiliense, 2003.

RIBEIRO, Darcy. O povo brasileiro: a formação e o sentido do Brasil. São Paulo: Global, 2015.

ROMERO, Sílvio. Cantos populares do Brasil. Rio de Janeiro: Livraria Francisco Alves, 1897.

ROMERO, Sílvio. Compêndio de história da literatura brasileira. Rio de Janeiro: Imago Ed., Universidade Federal de Sergipe, 2001.

RAMOS, Graciliano. Vidas Secas. 98. ed. Rio de Janeiro: Record, 2005.

ROSA, João Guimarães. Grande sertão: veredas. Rio de Janeiro: Nova Fronteira, 2006.

SCHWARCZ, Lília Moritz. O espetáculo das raças: cientistas, instituições e questão racial no Brasil - 1870 - 1930. São Paulo: Companhia das Letras, 1993. https://doi.org/10.5585/ eccos.n 46.8915

TELES, Gilberto Mendonça. O lu(g)ar dos sertões. Juiz de Fora, v. 8, n. 16, jul/dez. 2009.

TORRES, Antônio. Essa terra. 26. ed. Rio de Janeiro: Record, 2014 .

VENTURA, Roberto. Estilo tropical: história cultural e polêmicas literárias no Brasil 1870-1914. São Paulo: Companhia das Letras, 1991.

Recebido em: 21/8/2018.

Aprovado em: 2/5/2019. 


\section{Cássia da Silva}

Universidade do Estado do Rio Grande do Norte (UERN)/Universidade Regional do Cariri (URCA) Orcid: https://orcid.org/oooo-0002-8951-5849

E-mail: cassia_silv@hotmail.com

Endereço: Rua Maria José Costa Barreto, 1585, Royal Ville, Barbalha - CE

CEP: 63180-000

\section{Raul Azevedo de Andrade Ferreira}

Universidade Regional do Cariri (URCA)

Orcid: https://orcid.org/oooo-0002-6269-8358

E-mail: raul.ferreira@urca.br

Endereço: Rua Santa Margarida, n/ ${ }^{\circ}$ 45, Mirandão,

Crato- CE

CEP: 63125250 